\title{
Pyogenic granuloma of the small bowel
}

A 61-year-old man was referred to our hospital because of melena and progressive anemia requiring transfusion. He was on hemodialysis because of diabetic nephropathy. Although upper gastrointestinal endoscopy, colonoscopy, and a computed tomography (CT) scan were all normal, a subsequent capsule endoscopy revealed a tumor and blood in the middle part of the small intestine ( $\bullet$ Video $\mathbf{1}$ ). Because both anterograde and retrograde single-balloon enteroscopy failed to reach the tumor and repeated transfusions were necessary, a laparoscopy was performed. The lesion was easily identified during surgery as it had caused a small-bowel intussusception ( $\bullet$ Fig. $\mathbf{1}$ ). The resected specimen showed a mulberry-like semipedunculated polyp $1.5 \mathrm{~cm}$ in diameter ( $\bullet$ Fig.2). Histological study revealed that the tumor was composed of a proliferation of capillaries with a dense inflammatory cell infiltrate in the lamina propria, consistent with a pyogenic granuloma ( $\bullet$ Fig.3). The patient's anemia has improved and his clinical course has been uneventful since the surgery.

Pyogenic granuloma, also known as lobular capillary hemangioma, is a benign vascular tumor of the skin and mucous membrane, usually arising on the extremities and oral mucosa. The nomenclature is misleading because pyogenic granuloma is unrelated to bacterial infection, although its real etiology is unknown. Possible triggers include mechanical in-

\section{Video 1}

Views from a capsule endoscopy in a 61-yearold man with melena and progressive anemia showing a polypoid mass and blood in the middle part of the small bowel.

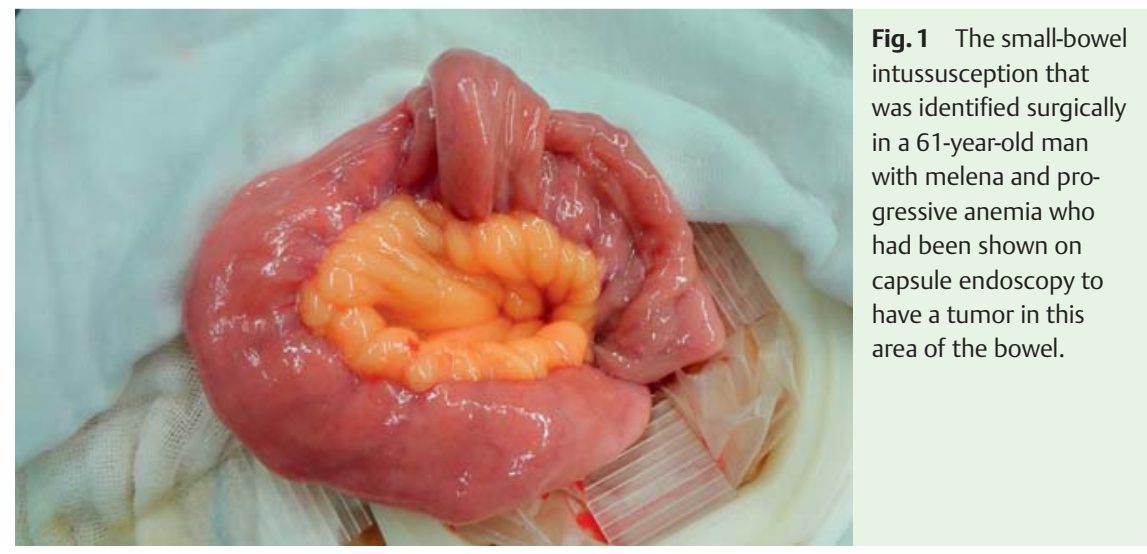

jury and pregnancy, but drug-induced pyogenic granuloma has also been reported $[1,2]$. As pyogenic granulomas bleed repeatedly and spontaneous regression is exceptional, surgical removal is a standard approach.

Pyogenic granuloma of the gastrointestinal tract is a rare condition: to date, less than 30 cases have been reported in the English literature [3-5]. Although they occur throughout the entire gastrointestinal tract, the small intestine is the commonest site, followed by the esophagus and the colon. Polypectomy is a reasonable option; however, the endoscopic approach is occasionally difficult in cases of small-bowel pyogenic granuloma. In some cases, despite their relatively small size $(0.7-3 \mathrm{~cm}$ in the reported cases), gastrointestinal pyogenic granulomas bleed easily and profusely. Capsule endoscopy and balloon enteroscopy may facilitate the management of small-bowel pyogenic granulomas.

Endoscopy_UCTN_Code_CCL_1AC_2AD

Competing interests: None

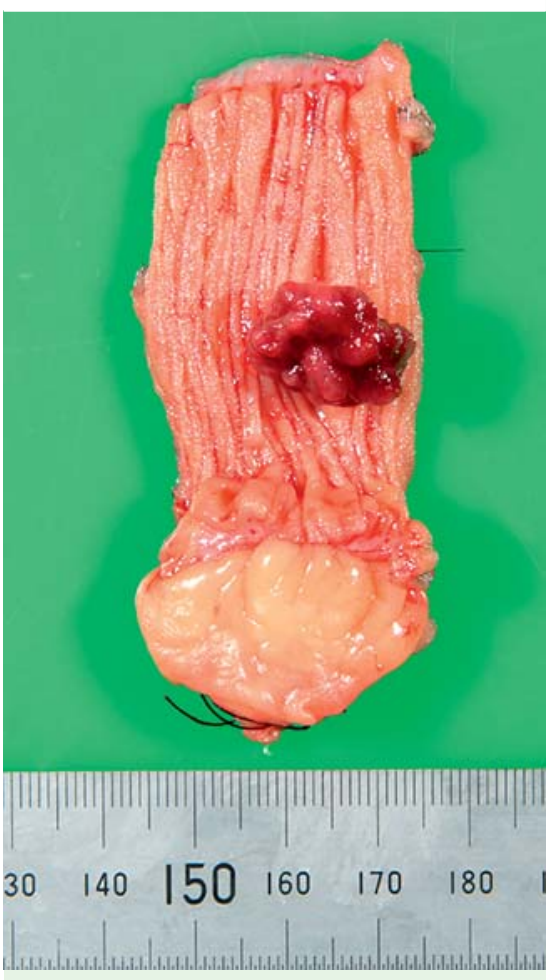

Fig. 2 Macroscopic view of the resected specimen of bowel containing the tumor. 

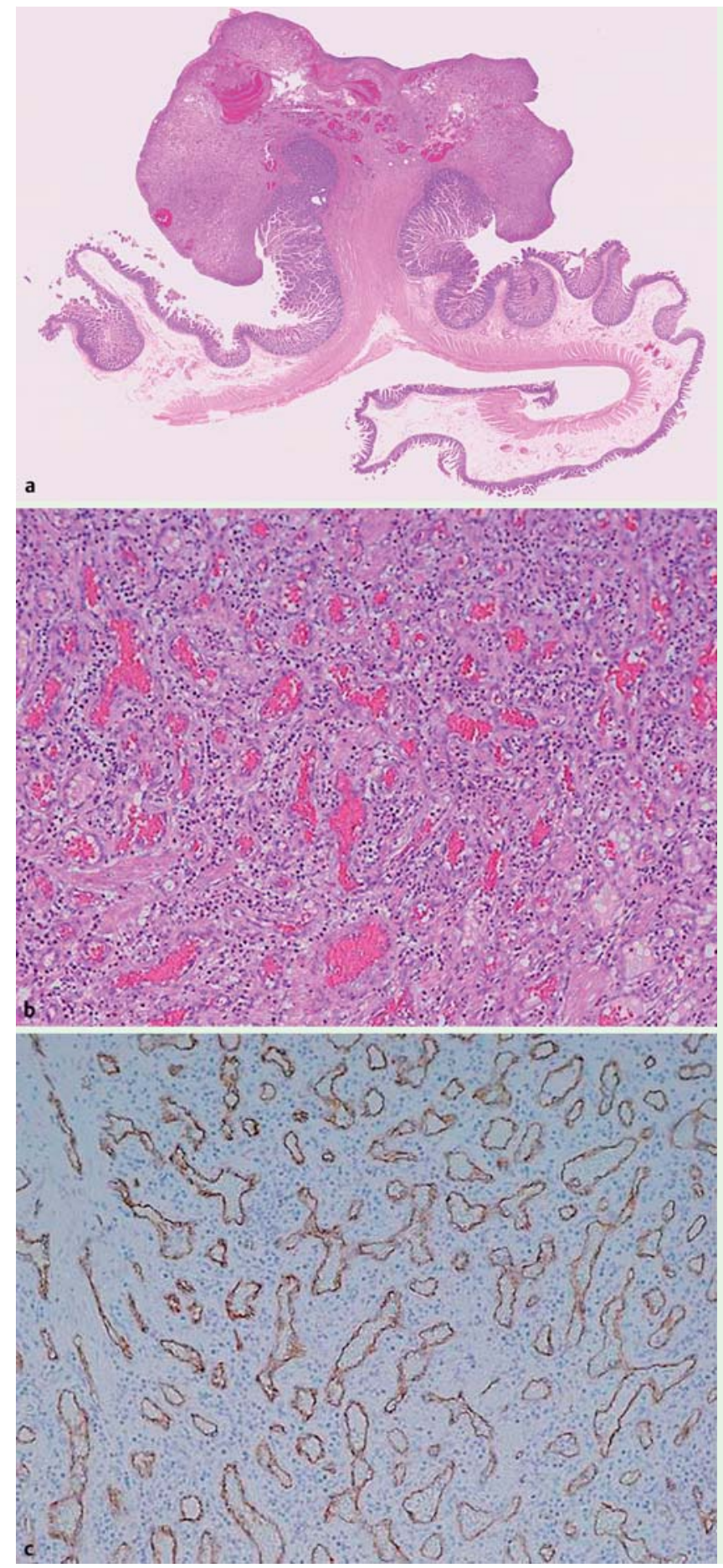

Fig. 3 Histologic examination of the resected tumor showing: a the appearance at low power (original magnification, $\times 2)$; $\mathbf{b}$ the proliferation of capillaries infiltrated with inflammatory cells (hematoxylin and eosin [H\&E] stain, magnification $\times 100$ ); $c$ the proliferation of endothelial cells, which were positive with CD34 immunostaining (magnification $\times 100)$.
K. Yamashita', Y. Arimura', M. Saito', T. lida ${ }^{1}$, R. Suzuki ${ }^{1}$, T. Niinuma ${ }^{1}$, T. Furuhata ${ }^{2}$, K. Kimura ${ }^{3}$, T. Ohta ${ }^{3}$, Y. Shinomura ${ }^{1}$

${ }^{1}$ First Department of Internal Medicine, Sapporo Medical University, Sapporo, Japan

2 First Department of Surgery, Sapporo Medical University, Sapporo, Japan

${ }^{3}$ Gastroenterology Center, Sapporo Higashi Tokushukai Hospital, Sapporo, Japan

\section{References}

1 Piguet V, Borradori L. Pyogenic granulomalike lesions during capecitabine therapy. $\mathrm{Br}$ J Dermatol 2002; 147: 1270 - 1272

2 Curr N, Saunders H, Murugasu A et al. Multiple periungual pyogenic granulomas following systemic 5-fluorouracil. Australas J Dermatol 2006; 47: 130-133

3 Moffatt DC, Warwryko P, Singh H. Pyogenic granuloma: an unusual cause of massive gastrointestinal bleeding from the small bowel. Can J Gastroenterol 2009; 23: 261 263

4 Kuga R, Furuya CK, Fylyk SN et al. Solitary pyogenic granuloma of the small bowel as the cause of obscure gastrointestinal bleeding. Endoscopy 2009; 41: E76-E77

5 Nagoya H, Tanaka S, Tatsuguchi A et al. Rare cause of obscure gastrointestinal bleeding due to pyogenic granuloma in the ileum detected by capsule endoscopy and treated with double balloon endoscopy. Dig Endosc 2010; 22: 71-73

\section{Bibliography}

Dol http://dx.doi.org/

10.1055/s-0032-1326119

Endoscopy 2013; 45: E9-E10

(c) Georg Thieme Verlag KG

Stuttgart · New York

ISSN 0013-726X

\section{Corresponding author}

\section{K. Yamashita, MD}

First Department of Internal Medicine Sapporo Medical University

S1W16, Chuo-ku

Sapporo 060-8543

Japan

Fax: +81-11-6112282

ykentaro@sapmed.ac.jp 